\title{
Characteristic of Chronic Complications in Type 2 Diabetic Patients Based on Asian Perspective
}

\author{
Corina Ong ${ }^{1 *}$
}

${ }^{1}$ Faculty of Medicine, Universitas Airlangga Surabaya, Indonesia

\begin{abstract}
A B S T R A C T
Introduction: Indonesia is in 6th place with the most diabetes mellitus cases globally. Long-term exposure to hyperglycemia that can be seen in chronic type 2 diabetes mellitus patients can cause macrovascular and microvascular complications. This complication contributes to the increased mortality rate in Indonesia.

Methods: This research uses a cross-sectional study by studying the medical record of type 2 diabetes mellitus patients, such as age, duration of diabetes mellitus, HbA1C levels, blood pressure, lipid profile, macrovascular and microvascular complication. The data obtained is reviewed descriptively.

Results: Most type 2 diabetes mellitus patient is between 55-64 years (39.4\%), mean of 55.75[CW2] ( $\mathrm{SD}=9.7$ ). Most patients suffer from type 2 diabetes mellitus for $\geq 5$ years $(61 \%)$. Meanwhile, the number of type 2 diabetes mellitus patients with uncontrolled $\mathrm{HbA} 1 \mathrm{C}$ levels $(\geq 7.0 \%)$ is $79 \%$, mean of 8.4 ( $\mathrm{SD}=1.8)$. Most type 2 diabetes mellitus patients do not experience hypertension [CW3] (77.8\%) and experience dyslipidemia (94.3\%), with the most prevalent lipid abnormality being high LDL (30.9\%). Besides, most type 2 diabetic patients have microvascular complications (57\%), with the most common complication being diabetic neuropathy (45.6\%), and the other microvascular complications are diabetic nephropathy (33.7\%) and diabetic retinopathy (20.7\%). While macrovascular complications are $43 \%$, the most common complication is a diabetic foot (29.9\%), and the other macrovascular complications are coronary heart disease $(27.8 \%)$, peripheral arterial occlusive disease $(22.9 \%)$, and stroke (19.4\%). Conclusion: All variables, including age, HbA1C levels, blood pressure, and lipid profile comparison, show similar results with Asia's other countries. Meanwhile, the duration of type 2 diabetes comparison is not identical with the other country in Asia.
\end{abstract}

Keywords: Chronic complications, Type 2 diabetes mellitus, Asian perspective

Correspondence: Corina Ong

E-mail: corinanaong@gmail.com

Article history: $\bullet$ Received 8 September $2021 \bullet$ Received in revised form 15 October $2021 \bullet$ Accepted 2 November $2021 \bullet$ Available online 31 January 2022

\section{INTRODUCTION}

Diabetes mellitus is a severe problem in the world, especially in Indonesia. In 2017, the International Diabetes Federation research results stated that the prevalence of people with diabetes mellitus in the world is 425 million people and will increase to $48 \%$, which is 629 million people in 2045 . Meanwhile, the prevalence of diabetes mellitus in Southeast Asia will increase to $84 \%$ in 2045 . Indonesia is the 6th place with most diabetes mellitus sufferers globally, with 10.3 million people. In contrast, the population in Indonesia who has diabetes mellitus but has not been diagnosed with diabetes mellitus is $73.7 \%$. In addition, the mortality rate of people with diabetes mellitus in Southeast Asia in 2017 reached $51.5 \%$. This states that the problem of diabetes mellitus is still a severe problem in the community (International Diabetes Federation, 2017).

Diabetes mellitus is a metabolic disease characterized by hyperglycemia. Hyperglycemia can cause pathological conditions and severe physiological changes in various target organs. This is dangerous because hyperglycemia has not shown symptoms in the community (asymptomatic), so it can cause significant clinical symptoms (American Diabetes Association, 2017). Risk factors for diabetes mellitus can be divided into risk factors that can be modified and cannot be modified. Risk factors that can be modified include unhealthy behavior, such as excessive weight, abdominal or central obesity, lack of physical activity, hypertension, dyslipidemia, unhealthy and unbalanced diets, uncontrolled Impaired Glucose Tolerance (IGT), and smoking. At the same time, the risk factors that cannot be modified are race and ethnicity, age, gender, family history of diabetes mellitus, etc. (Health Ministry of the Republic of Indonesia, 2014). Long-term hyperglycemia without significant control of various risk factors can cause both macrovascular and microvascular complications. Macrovascular complications include coronary heart disease, stroke, peripheral arterial occlusive disease, and diabetic foot. While microvascular complications are diabetic nephropathy, diabetic retinopathy, diabetic neuropathy, erectile dysfunction, and periodontal disease (Permana, 2000).

Chronic complications in the community can add new problems, such as hemodialysis, heart bypass, etc. $13.9 \%$ of patients with diabetes mellitus have to undergo hemodialysis. Patients with diabetes mellitus have a higher risk of end-stage renal failure until 3.13 times (Taneva et al., 2016). Meanwhile, $25 \%$ of patients with diabetes mellitus have to undergo coronary artery bypass graft (CABG) therapy (Aronson and Edelman, 2014). Chronic complications due to type 2 diabetes mellitus also increase mortality worldwide. One of the chronic complications is 
cardiovascular complications. Cardiovascular complications can cause death in 27 people out of 1,000 who suffer from type 2 diabetes mellitus, where one-third of them suffer strokes. In contrast, one in four suffer from coronary heart disease (International Diabetes Federation, 2017). Therefore, it is important to determine the chronic complications of type 2 diabetes mellitus patients in Dr. Soetomo Hospital.

\section{METHODS}

This research uses a cross-sectional study by studying the medical record of type 2 diabetes mellitus patients, such as age, duration of diabetes mellitus, HbA1C levels, blood pressure, lipid profile, macrovascular and microvascular complication. The data obtained is reviewed descriptively. The population is all of type 2 diabetes mellitus patients treated in Endocrine Clinic, Dr. Soetomo Hospital, from July until September 2017. The sample uses a total sampling of type 2 diabetes mellitus patients who suffers macrovascular and microvascular complications. Criteria for inclusion in this study are all type 2 diabetes mellitus patients. Meanwhile, the criteria for exclusion are patients who do not suffer from type 2 diabetes mellitus. The data obtained is then analyzed correctly using SPSS software, Microsoft Excel, and Microsoft Word.

\section{RESULTS}

The total number of samples in this study is 1483 patients with type 2 diabetes mellitus in Endocrine Clinic, Dr. Soetomo Hospital. Based on Table 1, most type 2 diabetes mellitus patients are between 55-64 years, which is 584 patients $(39.4 \%)$. While a minor type 2 diabetes mellitus patient is 15-24 years. The average age of type 2 diabetes mellitus patients treated at Dr. Soetomo from July to September 2017 was $55.75(\mathrm{SD}=9.7)$.

Table 1. Type 2 Diabetes Mellitus Patients Based on Age

\begin{tabular}{ccc}
\hline Age & $\mathrm{n}$ & $\%$ \\
\hline $15-24$ & 5 & 0.3 \\
\hline $25-34$ & 21 & 1.4 \\
\hline $35-44$ & 141 & 9.5 \\
\hline $45-54$ & 477 & 32.2 \\
\hline $55-64$ & 584 & 39.4 \\
\hline $65-74$ & 234 & 15.8 \\
\hline$>75$ & 21 & 1.4 \\
\hline Total & 1483 & 100 \\
\hline Average & $55.75 \pm 9.7$ \\
\hline
\end{tabular}

Among 1,483 outpatients with type 2 diabetes mellitus, the patient's medical record data about the duration of type 2 diabetes mellitus can be obtained in 220 patients. The number of patients that suffers type 2 diabetes mellitus with less than five years are 79 patients $(35.9 \%)$, more than five years are 134 patients $(61 \%)$, and no previous history of diabetes mellitus or just knowing the disease when visited Dr. Soetomo Hospital are seven patients (3.1\%).

The patient's medical record data on $\mathrm{HbA1C}$ levels that can be obtained is 224 patients from 1483 outpatients. The number of patients that with $\mathrm{HbA1C}$ levels $\geq 7.0 \%$ are 177 patients $(79 \%),<7 \%$ are 47 patients $(21 \%)$. The average obtained is $8.4 \pm 1.8$. Meanwhile, the patients with hypertension are 196 patients $(22.2 \%)$, while patients who do not have hypertension are 686 patients $(77.8 \%)$ from 882 patients' medical record data on $\mathrm{HbA} 1 \mathrm{C}$ levels.

Among 1,483 outpatients with type 2 diabetes mellitus, the patient's medical record data on $\mathrm{HbA} 1 \mathrm{C}$ levels that can be obtained was 210 patients. The patients with dyslipidemia are 198 patients $(94.3 \%)$, while patients who do not suffer dyslipidemia are 12 patients (5.7\%). Meanwhile, among patients who experience dyslipidemia, the detail of lipid fraction abnormalities that can be known is 192 patients. Data provided in Table 6 shows that each patient could experience more than one lipid fraction abnormality. Based on Table 2, it can be seen that most patients with type 2 diabetes experience high LDL (30.9\%).

Table 2. Type 2 Diabetes Mellitus Patients Based on Lipid Fraction Abnormalities

\begin{tabular}{lcc}
\hline \multicolumn{1}{c}{ Lipid Fraction } & $\mathrm{N}$ & $\%$ \\
\hline High total cholesterol & 102 & 26.9 \\
\hline High TG & 108 & 28.5 \\
\hline High LDL & 117 & 30.9 \\
\hline Low HDL & 52 & 13.7 \\
\hline Total & 379 & 100 \\
\hline
\end{tabular}

Most type 2 diabetic patients have microvascular complications (57\%), with the most common complication being diabetic neuropathy $(45.6 \%)$, and the other microvascular complications are diabetic nephropathy $(33.7 \%)$ and diabetic retinopathy (20.7\%). While macrovascular complications are $43 \%$, the most common complication is a diabetic foot $(29.9 \%)$, and the other macrovascular complications are coronary heart disease $(27.8 \%)$, peripheral arterial occlusive disease $(22.9 \%)$, and stroke $(19.4 \%)$.

\section{DISCUSSION}

Based on Basic Health Research in Indonesia, the most prevalent age in Indonesia that suffers diabetes is 55-64 years $(4.8 \%)$, following after that is $65-74(4.2 \%)$, and 45 - 54 years (3.3\%) (RISKESDAS, 2013). Meanwhile, based on the Health Ministry of the Republic of Indonesia, the age group of 55 - 64 years is classified as a productive age population (Ministry of Health Republic of Indonesia, 2017). In Southeast Asia, the highest age group that suffers diabetes mellitus is 50 - 59 years in men and $60-69$ years in women (International Diabetes Federation, 2017).

The highest proportion of type 2 diabetic duration is $\geq 5$ years $(61 \%)$. Meanwhile, research in Iraq shows that most type 2 diabetes mellitus duration is $<5$ years (Khudhair, 2009). The low awareness may cause this to do initial screening in patients with type 2 diabetes mellitus and the low level of public knowledge about the early clinical symptoms of type 2 diabetes mellitus.

Based on the HbA1C level of the patient with type 2 diabetes mellitus is $\geq 7 \%(79 \%)$, while the average is 8.4 $(\mathrm{SD}=1.8)$. Meanwhile, the target of HbA1C levels in type 2 diabetes mellitus is $<7 \%$ (PERKENI, 2015). It means most type 2 diabetic patient still does not fulfill the target of HbA1C levels. Research in Palestine shows similar results. The most prevalent $\mathrm{HbA} 1 \mathrm{C}$ level is $\geq 7 \%$ (16.1\%), while the average is 9.21 ( $\mathrm{SD}=2$ ) (Al-Halaweh et al., 2017).

Most type 2 diabetic patients in Dr. Soetomo Hospital do not have hypertension (77.8\%). Meanwhile, research in 
Palestine shows similar results. The proportion of patients with type 2 diabetes mellitus in Palestine with hypertension is $23 \%$ (Al-Halaweh et al., 2017), which means most do not have hypertension (77\%).

Meanwhile, most type 2 diabetic patients in Dr. Soetomo Hospital have dyslipidemia (94.3\%), with the most prevalent lipid fraction abnormalities being high LDL $(30.9 \%)$. Meanwhile, similar results are shown in Nepal. Research in Nepal shows that the percentage of type 2 diabetes mellitus patients who suffer dyslipidemia is $85.33 \%$, with the most prevalent lipid fraction abnormalities being high LDL (55.33\%) followed by low HDL (49.33\%) (Shrestha HK and Khanal L, 2017).

The most common chronic complications in type 2 diabetes mellitus patients are microvascular complications (57.3\%), while macrovascular complications are $42.7 \%$. Similar results are also found in Saudi Arabia and Korea, that the most prevalent chronic complications are microvascular complications (Alaboud et al., 2016; Rhee et al., 2011). At the Dr. Soetomo Hospital, the most common complication of type 2 diabetic patients is diabetic neuropathy, $45.6 \%$. Meanwhile, research in Saudi Arabia is diabetic nephropathy (Alaboud et al., 2016) and diabetic retinopathy in Korea (Rhee et al., 2011).

\section{CONCLUSION}

All variables, including age, $\mathrm{HbA} 1 \mathrm{C}$ levels, blood pressure, and lipid profile comparison, show similar results with the other countries in Asia. Meanwhile, the duration of type 2 diabetes comparison is not identical with the other country in Asia.

\section{CONFLICT OF INTEREST}

The authors declare there is no conflict of interest.

\section{REFERENCES}

Alaboud A, Tourkmani A, Alharbi T, Alobikan A, Abdelhay O, Batal S, Alkhashan H, Mohammed U. 2016. Microvascular and macrovascular complications of type 2 diabetic mellitus in Central, Kingdom of Saudi Arabia. Saudi Med J 37.

Al-Halaweh A, Davidovitch N, Almdal T, Cowan A, Khatib S, Nasser-Eddin L, Baradia Z. 2017. Prevalence of type 2 diabetes mellitus complications amongPalestinians with T2DM. Science Direct. 11.

American Diabetes Association. 2017. Standards of Medical care in diabetes - 2017. The Journal of Clinical and Applied Research and Education 40.

International Diabetes Federation. 2017. IDF Diabetes Atlas Eighth Edition 2017. International Diabetes Federation.

Health Ministry of the Republic of Indonesia. 2014. Diabetes Situation and Analysis. Center for Data and Information of the Health Ministry of the Republic of Indonesia

Health Ministry of the Republic of Indonesia.2017. Indonesian Health Profile 2016. Health Ministry of the Republic of Indonesia.

Indonesian Endocrinology Society (PERKENI). 2015. Konsensus Pengelolaan dan Pencegahan Diabetes Mellitus Tipe 2 di Indonesia 2015.

Permana H. 2000. Chronic complications and comorbidities in diabetes. Medical Care.

Rhee S, Chon S, Kwon M, Park I, Ahn K, Kim I, Kim S, Lee H, Koh K, Kim D, Baik S, Lee K, Nam M, Park Y, Woo J, Kim Y. 2011. Prevalence of chronic complications in korean patient with type 2 diabetes mellitus based on the Korean National Diabetes Program. Diabetes \& Metabolism Journal 35.

Shrestha HK, Khanal L. 2017. Prevalence and Pattern of Dyslipidemia among Type 2 Diabetes Mellitus Patients in a Tertiary Center Hospital of Nepal. Endocrinology \& Metabolism International Journal 4(3):00084. 